\title{
Socio-Spatial Research on Logistics and Its Impact on Urban Environment: A Review
}

\author{
José A. López-Sánchez*, Beltrán Roca
}

University Institute of Research on Social Sustainable Development, University of Cádiz, Av. de la Universidad 4, 11406 Jerez de la Frontera, Spain

Corresponding Author Email: beltran.roca@uca.es

https://doi.org/10.18280/ijsdp.160106

Received: 17 November 2020

Accepted: 29 January 2021

\section{Keywords:}

logistics, urban change, urban planning, socio-spatial relations

\begin{abstract}
This review article attempts to respond to the following research questions: how has evolved socio-spatial analysis on logistics, which are the most studied types of this economic activity, and the major impacts of logistics on urban space. This article draws on a systemized bibliometric analysis to identify the main tendencies in logistics' spatial study. It identifies four clusters of literature that put interest on different subtopics and approaches. The review reveals the current hegemony of applied research that focuses on sustainability, streamlining, and technology, mainly from the USA and China, despite research on globalization and industry. In fact, concerning the urban space, the most vivid academic discussion revolves around the location of warehousing and transport activity within cities. Finally, the article highlights the lack of critical perspectives on logistics and socio-spatial conflicts generated by logistics extension in mainstream academic literature. The analysis concludes that socio-spatial disputes related to logistics remain understudied and, consequently, further research should be conducted on this field.
\end{abstract}

\section{INTRODUCTION}

The globalization process and the developments in digital technologies, robotics, Big Data, and artificial intelligence have paved the ground for the increasing relevance of logistics in contemporary societies. Logistics refers to a complex and diverse set of activities dedicated to the transformation and distribution of goods and information. Logistics includes 'the material supply of production, the core distribution and transport function, wholesale and retail and also the provision of households with consumer goods as well as the related information flows' [1]. Today, the rise of global supply chains demands higher efforts for connecting the points of origin of raw materials to production places and, subsequently, to consumers. The growth of door-to-door or last-mile delivery service have both boosted the relevance of transportation, warehousing, and distribution in the market, and posed new challenges to economic organizations [2-4], including the labor movement [5-8].

Logistics activity introduces spatial changes both in the production sphere and in the urban structure. At the beginning of the twenty-first century, scholars pointed out that the expansion of logistics was associated with global city-regions $[9,10]$. Several authors focused on how globalization was transforming urban space.

The seminal work of Scott and Storper [11] suggests that urban planners resolve the contradictions between capital and labor by means of intervening in land markets. Many researchers have followed this research line, paying attention to how global city-regions, which have an intense sea and freight activity, play a critical role in global logistics [12].

Besides, recent works have pointed out that the change of the location of determinate economic activities, such as micro- work and other gig-works, are changing (to a certain extent) work trajectories and, consequently, labor's spatial practices [13]. Further research has paid attention to how the platformization of urban mobility is transforming the production of urban space. The use of digital platforms for urban transit, such as Uber, Lyft, Blablacar, and others, whose technology deepens the geospatial dimension of platforms, is boosting the rise of platform urbanism, marked by the strong interrelation between urban space and platform structures [14]. In particular, platforms are informalizing mobility in the Global North and formalizing it in the Global South, producing an extraordinary variegated and diverse landscape [15]. The authors argue that in highly informal labor markets of the Global South, platforms provide an opportunity to formalize partially certain economic activities that were previously unregulated.

The general hypothesis of this review article is that logistics is today at the center of urban change and governance. For this reason, the article attempts to respond to the following research questions:

Q1: How has evolved socio-spatial analysis of the logistics sector in the last 20 years?

Q2: What types of logistics activities are more studied from a spatial perspective?

Q3: What are the impacts of logistics on urban space organization according to the specialized literature?

This review parts from the premise that the analyses on the spatial impact of logistics (Q3) should be studied in the light of the evolution of scientific literature in this domain (Q1 and Q2).

The article is structured as follows. First, it explains the methodology used for conducting a systematic literature review, including selecting a sample of publications and using 
computer software for bibliometric analysis. Second, the article shows the results of the study. This section is divided into three parts, which correspond with the article's three objectives: identifying trends in logistics spatial research, the most studied types of logistics activities, and the impact of logistics on urban space. Finally, the article synthesizes the main conclusions of the review and reflects on possible future research.

\section{METHODOLOGY}

The impact of economic activity on socio-spatial relations and urban planning is highly heterogeneous. Its study includes various disciplines, methodological approaches, and topics. For this reason, this bibliometric analysis employs a quantitative and systematized review of the literature. The examination allows us to discover the links among the multiplicity of approaches to the phenomenon. This type of review contributes to identify blind spots in current research and to propose an agenda for further research [16-20]. Bibliometric studies are drawn mainly on quantitative analysis of publications about a specific phenomenon [21]. This article uses a structured method for addressing the proposed research questions, maximizing methodological accountability and reliability.

Systematized reviews use a rigorous procedure for understanding in a straightforward manner how topics emerge and develop in a particular field of research [22, 23], in this case, in the ambit of social sciences. Thus, it is possible to measure the evolution of a specific research área through scientific production through a particular time-lapse. As Linnenluecke et al. [24] suggest, bibliometric analysis can examine the intellectual structure, fields of knowledge, geographical áreas, themes, research methods, and the level of maturity of a discipline's topics or scientific journals.

This systematized review is structured as follows. First, it has been examined if the databases and approaches employed are appropriate. It has been checked the suitability of the methodology for exploring the existing literature on the field of inquiry. The selected database was the Web of Science Core Collection (WoSCC) because it contains those peer-reviewed journals with a more international scope. The authors have devoted three months (from June to September 2020) to the exhaustive search within this database. In particular, the search contained the following terms and boolean operators: 'logistics' and ('urban space' or 'urban planning' or 'city' or 'urbanism' or 'geography' or 'space' or 'spatiality'), in its titles, abstracts, and keywords. The time-lapse was from 2000 to 2020 (until September).

The search showed 622 publications with 7,288 citations. An initial analysis showed that part of these publications addressed the spatiality and urban impact of logistics in an unsubstantial manner, and several of them included the term 'logistics' not referring to the economic activity under study, but with other meanings (such as employing logistic regression in its methodology). The most cited 50 publications were selected to make more operational the analysis. It included 46 articles in scientific journals and four papers in conference proceedings. After excluding the items that did not directly address logistics activity, the final sample was reduced to 41 publications.

Secondly, several analysis categories were selected to classify and quantify the data: spaces, country, most cited authors, terminology, and journals. This bibliometric analysis provided an objective approach for exploring tendencies and research performance, serving as a complementary method for conventional literature revision [25]. Content analysis was conducted employing the computer software Vosviewer, version 1.6.14, developed by Van Eck and Waltman [26]. This software allows us to visualize bibliometric networks using multiple parameters. The software produces graphics and maps of relationships, clusters among authors, institutions, countries, and keywords from a bibliographic database. It has allowed us to identify the most influential countries, authors, and research topics in this field of inquiry, following the example of other systematic reviews [27]. Finally, in a third stage, the authors analyzed the results. They conducted a conventional observation of the cluster of publications that contributed to responding to the article's research questions.

On the other hand, the researchers have carried out a conceptual analysis that has allowed them to investigate the main topics related to cities and logistics and to know the structure, evolution, and trends related to these concepts. For this analysis, they have used the SciMAT software, which offers a visual map of the evolution of the concepts or nodes that encompass the critical words of the most relevant authors obtained from their publications. Besides, this software has facilitated various strategic analyses for the most pertinent concepts, locating them in different categories according to Callon's centrality and density indicators [28, 29]. Subsequently, a second data search was carried out in the Web of Science (WOS) to export them to SciMAT. This time using the advanced search option, including journal title, publication date, author details (name and affiliation), article title, keywords, abstract, and citation count.

Finally, it was necessary to homogenize the database once exported to SciMAT from WoS to obtain consistent results. With SciMAT and from the Group Set module, the authors registered duplicities. They homogenized the terms by word similarities that alluded to the same authors, publications, or sources to subsequently carry out manual work to include authors' keywords by concepts or specific nodes. In this way, they managed to limit the automatic assignment of many of these terms only by the syntax criterion, which, although very practical, sometimes relates the keywords in nodes in the wrong way. They thus used 903 concepts containing the most relevant keywords [24]. This analysis gave them three representations: strategy diagrams, cluster networks, and areas of evolution [26].

\section{RESULTS}

\subsection{Socio-spatial analysis of the logistics industry}

As explained in the previous section, the search in the Web of Science of the terms under scrutiny -'logistics' and ('urban space' or 'urban planning' or 'city' or 'urbanism' or 'geography' or 'space' or 'spatiality')-, focused on the categories: 'Geography' and 'Urban Studies.' The search had 622 results between the years 2000 and 2020 .

The first analysis consisted of the relationships among the different keywords of the 622 publications (see Figure 1).

Figure 1 shows that the analysis of the interrelations among keywords allows identifying four different clusters, referring to specific research topics and approaches: 


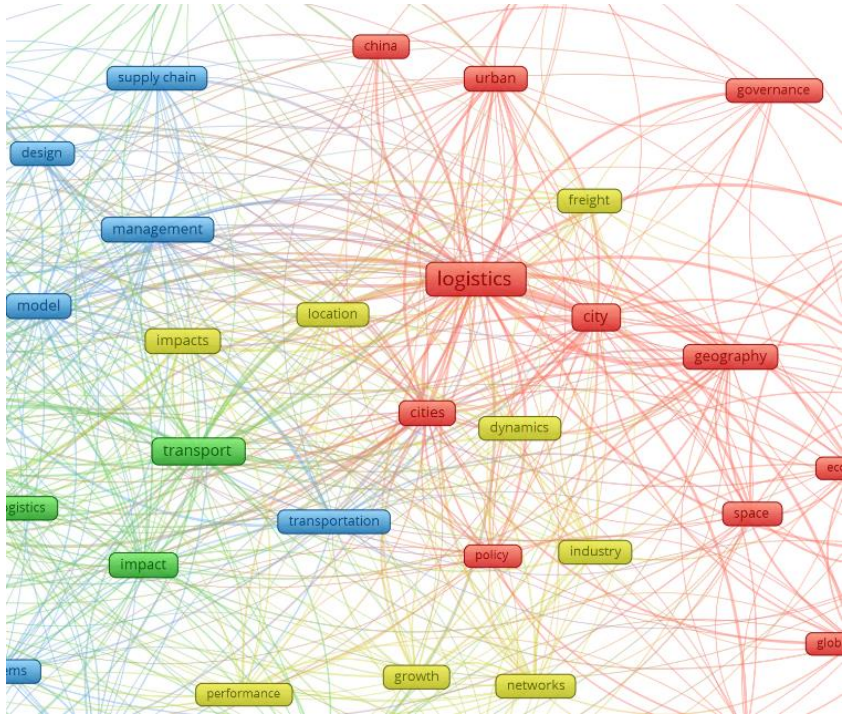

Figure 1. Keywords analysis

Source: Own elaboration.

- Cluster 1, located on the left of the graphic in red color, whose terms are related to economics, politics, and logistics.

- Cluster 2, in yellow, represents publications interested in the spatiality of industry and innovation. This cluster overlaps partially with other clusters.

- Cluster 3, in blue, shows concepts related to systems, challenges, and design.

- Cluster 4, in green, highlights terms related to transport and sustainability.

Figure 2 completes the previous analysis, including the temporal distribution from the year 2000 to today. The more recent concepts are related to sustainability, optimization, and technology. The words that prevailed in the oldest publications were linked to industry and globalization.

This tendency can reflect absolute exhaustion in the use of terms within the scientific field but also the existence of 'academic fashions' and branding-strategies that operate within the Academy [30, 31].

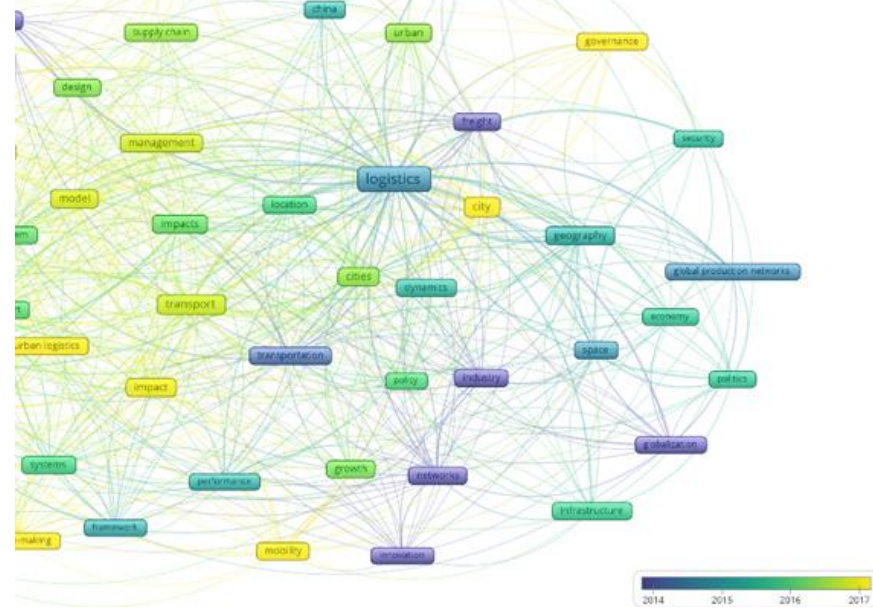

Figure 2. Keywords analysis by the temporal distribution Source: Own elaboration.

Besides, it must be noted that a significant part of clusters two and three are distributed by the end of the temporal line of 2015. However, some of the most recent publications belong to the first cluster (for example, with economics, security, and politics).
Regarding the frequency of the categories, it must be pointed out that the term 'logistics' appears 135 times in the first cluster, and 'city' appears 38 times.

In the fourth cluster, the most frequent term is 'city logistics,' followed by 'geography' that appears 30 times. There are no concepts within clusters two and three with the same frequency as in the other two clusters. However, in the third cluster, the term "model" appears 32 times, and the Word "impacts" appears 24 times in the second cluster.

The analysis also paid attention to the number of citations of the different resources (including journals and conference proceedings, such as the Second International Green CitiesGreen Logistics conference, that had 24 citations. Figure 3 reflects the most cited journals in the analyzed literature. In this graphic, the size of the nodes reflects the number of citations. The most cited resource is the journal Sustainability, with 91 citations, followed by the Journal of Transport Geography, whose publications on the topic received 56 citations.

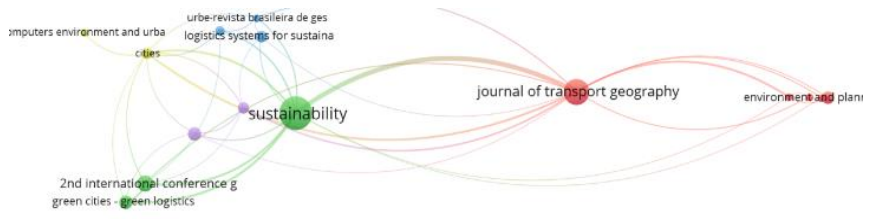

Figure 3. A cluster of citations by resources Source: Own elaboration from vosviewer

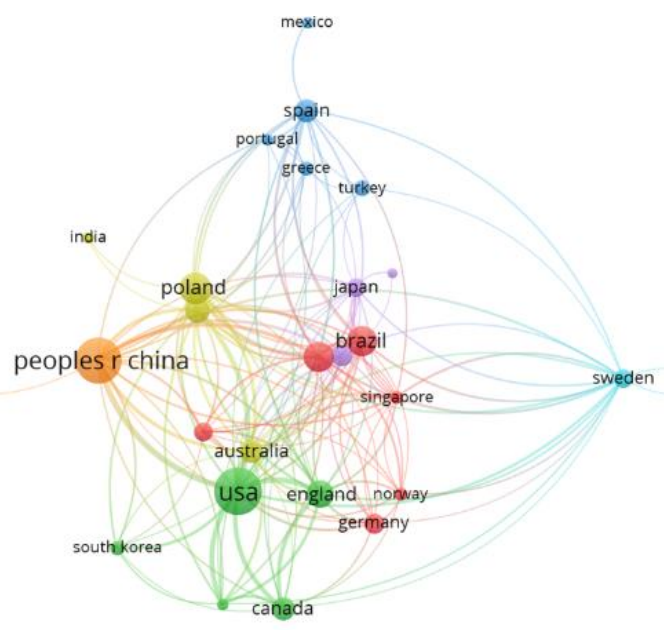

Figure 4. Co-authorship cluster by country Source: Own elaboration from vosviewer

Finally, Figure 4 reflects an analysis of clusters by coauthorship. It is noteworthy the prevalence of six groups of countries. The most prominent clusters are the purple and orange ones, due to the high participation of authors from the USA and China.

It can be observed in Figure 4 that the two countries with higher citation marks are the USA and the Popular Republic of China, with 103 and 96, respectively. Besides, the authors of both countries have connections with all the clusters, similar to Japan, although this country does not show such a high impact. After the USA and China, the number of citations stands out Brazil and Italy, with 42 citations. These two countries belong to the red cluster and show a strong link to Japan. These countries are followed by several European countries, such as Germany, Spain, the UK, and France. 
Analyzing the numbers by continent, Europe had 327 citations, America 176, and Asia 157.

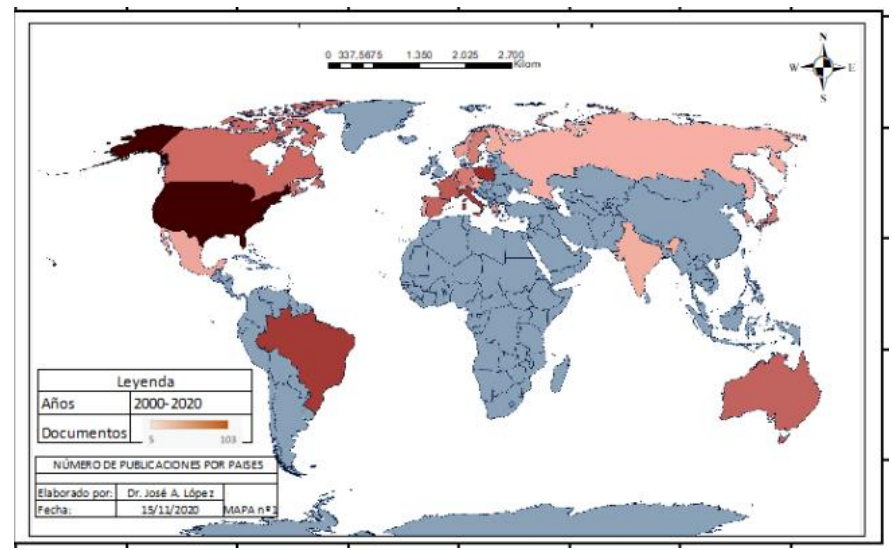

Figure 5. World map of the bibliographic production on the spatiality of logistics

Source: Own elaboration

Finally, Figure 5 shows the countries whose authors have published more documents from the sample. The leading position of the USA can be observed.

Also, the notable academic production of authors from Brazil, Italy and Poland, followed by Canada, Spain, France, the Netherlands, Sweden, Japan and Australia.

Figures 1 to 5 reflect that in geography and urban planning, traditional international powers countries have a leading role. Still, emerging countries, such as China, Brazil, and India, are gaining a clear relevance.

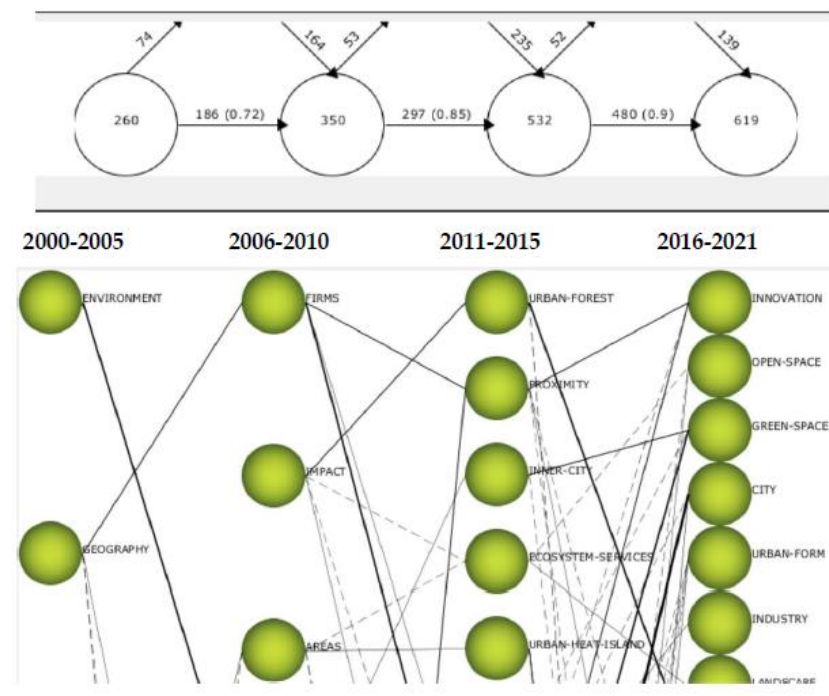

Figure 6. Analysis thematic evolution (2000-2021) Source: Own elaboration with SciMAT.

As a complement to the previous analysis, a conceptual analysis has been carried out to quantify and analyze the presence, meaning, and relationships, together with the evolution of the most recurrent terms existing in the most cited publications in our field of study. It allowed the authors to make inferences over time about the evolution of the analyzed concepts, identifying the relationships between them and the current trends or driving concepts on which research is currently focused. They also wanted to know where research is heading. To do this, they employed a chronological evaluation map and different strategic analyses of the centrality-density of the most relevant concepts.

They first carried out a temporal analysis to find out which concepts and how they have evolved over the four stages into which they have divided the overall period 2000-2021 (Figure 6).

All content analysis involves the first step of coding, in this case, based on the most important keywords. On this occasion, all the keywords that respond to the concept due to the abundance of terms have been compiled in a single group with the same name. The authors also used an inclusion index to detect the links between the different themes to define thematic areas (lines).

In the first phase (2000-2005), research focused mainly on 260 concepts related to geography and the environment. In the second phase (2006-2010), it can be observed that scientific production intensifies, including 164 new terms or keywords. When added to the 186 that had been maintained from the previous stage, give a total of 350 terms. To these it must be added the 235 new words from stage 3 which, reaching the amount of 532 concepts grouped into urban-forest, proximity, inner-city, ecosystem services urban-heat-island. Therefore, this analysis makes it possible to differentiate concepts with reliable connections to themes. Some of them are even maintained from the first period (continuous lines), such as the relationship between geography, firms, proximity, and innovation. However, as can be seen, other concepts present weaker connections (dotted lines), although none of these are main concepts in the last stage despite the introduction of 139 new themes, reaching a total of 619 terms. At this stage, the fourth, current trends can be identified. The size of the circles in Figure 6 represents the result of the h-index by concepts during the four periods, in such a way that, focusing on the last phase, the most dynamic research concepts the citations obtained are "city" in first place, followed closely by "urbanspace", followed in order of relative importance by other concepts such as "urban-form" and "landscape" with a very similar h-index.

Besides, as anticipated in the methodology section, the authors have carried out a series of strategic density/centrality analyses of the most relevant concepts during the overall study period 2000-2021. One the one hand, they have analyzed the density or internal cohesion index of the main concepts. The intensity of the internal associations of a concept with keywords or terms of which it is composed represents the degree of development that a concept possesses concerning the others. On the other hand, on the abscissa axis, the authors have studied the centrality component or external cohesion index, which is obtained through the sum of the equivalence indices of all its external links, which in turn corresponds to the relationship that a specific node has with the others in the diagram (Figure 7).

In Figure 7 it can be see the 2000-2020 analysis in four differentiated periods. The first corresponds to the period 2000-2005, where it can be seen how on the first axis of coordinates the diagram identifies two groups tending towards the centrality of "values" and "environment". However, in those years, also appears a new theme, "city", which will be recurrent over the following years and until becoming hegemonic from 2015 onwards. The term "environment" was consolidated in the second period, while new terms such as "economy", "geography", etc. appeared. However, only the concept "economy" will be maintained until the present day. In the 2011-2015 period, the term “city' stands out, which will 
become the dominant theme five years later. In the last section of Figure 7 (2016-2020), it can be seen that "city", "innovation", "green-space", "urban-heat-island", and "urbanform" became the basic themes of existing research, with a high relationship with the other clusters or nodes of the diagram.
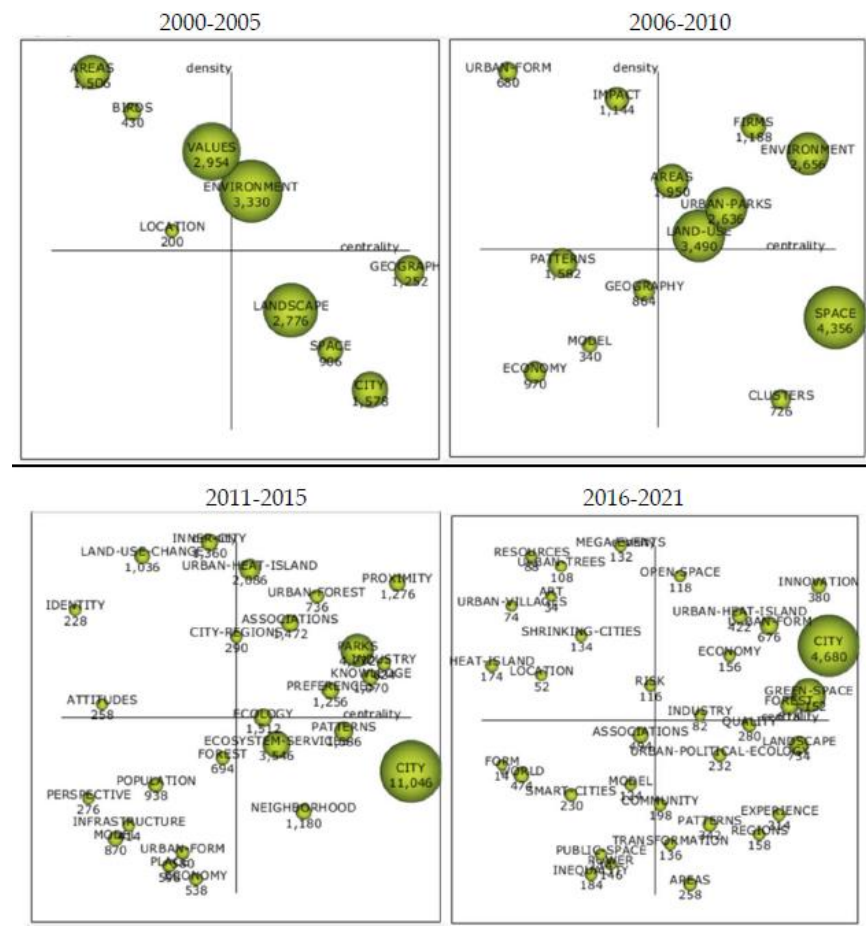

Figure 7. Strategy analysis Publications/Thematic evolution (2000-2020)

Source: Own elaboration with SciMAT.

The previous analysis has been completed with two additional strategic density-centrality diagrams, which consist of the concepts' location based on their respective h-indexes for the years 2010-2015 and 2016-2020 (see Figure 8).
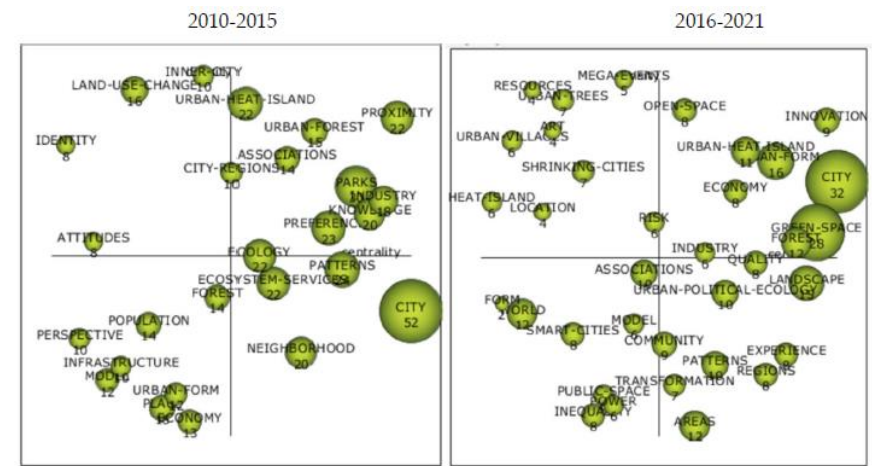

Figure 8. Strategy analysis Publications h-index/Sum Citations/Avarage Citations (2010-2021) Source: Own elaboration with SciMAT.

Thus, it can be observed the prevalence the concepts "city" and "green-space" in the h-index. "City" obtained an h-index of 32, which means that out of the total number of publications of this concept, 32 articles were cited more than 32 times. Therefore, this concept is basic and transversal in the subject analyzed in this article. As shown in the table above, it is followed by "Green-space", with an h-index of 28, and then by "Landscape" and "Urban-heat-island".

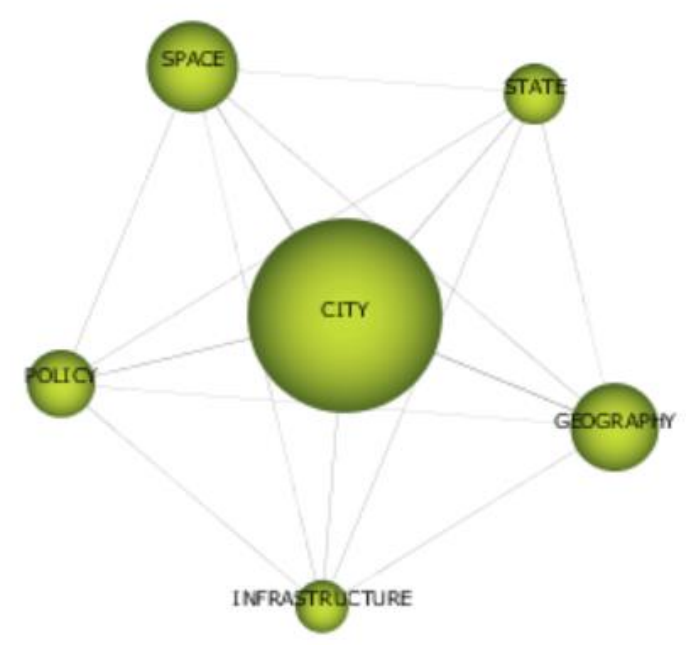

Figure 9. Strategy analysis Publications/Thematic evolution (2000-2021)

Source: Own elaboration with SciMAT.

Finally, the conceptualization analysis has been supported by the cluster network in shown in Figure 9. This figure helps the authors to identify the most relevant nodes and their interconnections with the driving concept with the greatest potential for development. The concepts are "space" and "geography".

\subsection{Types of logistics activities most studied from geography}

To respond to the second and third research questions of this article, a sample of the most 50 cited publications in 20002020 has been selected. A first filter excluded those publications that included the term 'logistics' in their title, abstract, or keywords. Still, it did not refer to logistics economic activity (for example, several articles that included the term 'logistic regression' in their methodology but addressed other types of social phenomena). Thus, the final sample included 41 publications, including articles in academic journals $(n=37)$ and papers in conference proceedings $(n=4)$.

Table 1. Frequency of types of logistics activities in the bibliographic sample

\begin{tabular}{c|c|c}
\hline $\begin{array}{c}\text { Type of logistic } \\
\text { activity }\end{array}$ & $\begin{array}{c}\text { Frequency in } \\
\text { publications }\end{array}$ & $\begin{array}{c}\text { Sample } \\
\text { reference }\end{array}$ \\
\hline Transportation & 36 & {$[12,33-34]$} \\
Earth & 15 & {$[32]$} \\
Sea & 6 & {$[33]$} \\
Air & 1 & {$[12]$} \\
Non-specific & 16 & {$[34]$} \\
Warehousing & 7 & {$[35]$} \\
Reverse logistics & 2 & {$[36]$} \\
TOTAL & $\mathbf{5 5}$ & \\
\hline
\end{tabular}

Source: Own elaboration

Of these 41 publications, the most part $(n=36)$ addressed specifically transport activity, while only seven addressed explicitly warehousing and two reverse logistics (see Table 1). It is worth saying that four publications addressed both transportation and warehousing. Regarding the type of transport, the central group of works was not specific $(n=16)$, 
pointed to several means of transportation indistinctively, or focused on earth transportation $(\mathrm{n}=15)$, freight activity, and rail. Specific publications on maritime $(n=6)$ and air $(n=1)$ transport were less frequent.

\subsection{The impact of logistics on urban structure}

The first cluster of literature in Figure 1 (in red) is the one that focuses more on the interrelation of urban space and logistics. This body of literature has paid attention to the impact of the logistics industry on cities. With this goal, this body of literature has studied to four different dynamics: the role of local regulations on logistics development; the decision-making process of authorities and urban planners in the context of globalization; the location of logistics infrastructures; and urban sustainability.

Firstly, several scholars have investigated the role of local regulation and urban structure on urban freight efficiency has been analyzed. For example, in a study of Spain, Muñuzuri et al. [37] underlined that inconsistent regulations, the lack of enforcement, and the obsolescence of policies, together with complex urban morphology, make the Spanish urban freight system highly defective. Besides, researchers have explored UK urban freight trends to inform decision-making about transport and land use [38].

Secondly, researchers have focused on how economic globalization impact on urban designers. Poelmans and Van Rompaey [39] assessed three different models for predicting future spatial urban patterns to respond to economic and environmental factors. They conclude that a hybrid model integrating determining factors (distance to the main roads, distance to the largest cities, employment potential, slope, and zoning status of the land) and neighborhood interactions are more accurate. Other studies have focused on port cities. Lee et al. [40], for example, have given evidence from Asian port cities. In particular, they have studied the cases of Hong Kong and Singapore. These cases illustrate how new tendencies, such as the integration of logistics and the transport revolution, together with globalization, are transforming port cities also in Asia. In particular, the authors propose the existence of an Asian model of global port hub city, defined by acquiring a leading position through overcoming space limitations and congestion with a dynamic growth (for example, complementing with the ports in the viticiny); and by prioritizing maritime economic activity over port activity. In this manner, Asian ports have developed a more 'symbiotic' with cities, in contrast to its international counterparts, in which socio-spatial conflicts between ports and cities have been more salient [41].

Thirdly, within the first cluster of literature, the most vivid academic discussion has revolved around the issue of the location of warehousing and transport activity within cities. Several studies have suggested the existence of a 'logistics sprawl,' that is, a tendency to displace logistics activity to suburban areas [33]. Cidell [32], within this approach, studied recent shifts in the location of warehousing and trucking from 1980 to today in the US. The author argues that there is a tendency towards decentralization and suburbanization of logistics within cities. The growth and internationalization of freight activity have led to the congestion of major ports and gateways, confirming what has been labeled 'choke points.' Planners have tended to move to inland distribution centers to decongest port areas. Also, logistics activities have moved from city centers to suburban sites (although certain US cities have concentrated their logistics infrastructures in the city centers under particular circumstances). In contrast, determinate case studies have found that logistics has focused on city cores in certain cities. Authors have called it the 'logistics anti-sprawl' [42].

The expansion of cities, effectively, has been explored in connection to logistics. O'Connor [12] employs a global city region framework to analyze global cities' relevance in logistics activity. Global city-regions are those expanses of built-up space surrounded by hinterlands 'marked by ramifying local institutions and an increasingly distinctive political identity, and, concomitantly, by a growing selfassertiveness on the global stage' [43]. The concept brings suburban areas into the debate on the global links and characterization of city cores. Drawing on previous research, O'Connor [12] argues that the extension of outsourcing in global cities has favored the rise of logistics within these regions. The author demonstrates that 44 global city logistics regions concentrated almost half of air freight and two-thirds of sea freight activity in 2006. These regions have been focusing on logistics activity since the 1990s. Besides, O'Connor [12] finds that regions with multiple airports and seaports tend to accumulate more logistics activity. Having multiple transport infrastructures and entries becomes a competitive advance for these regions, and thus, have to be seen as essential elements of planning initiatives.

Forthly, logistics has been studied from the point of view of its impact on urban sustainability. However, there is no consensus about the implications of this economic activity. While some authors have emphasized the potential of logistics methods for achieving more sustainable and efficient cities [44], other researchers have shown more critical perspectives. Within this critical line, Cowen [45] has argued that the expansion of logistics is transforming how urban planners and policymakers think of the city. Logistics, the author suggests, has put calculation at the center of the production of space, leading decision-makers to apply a cost-benefit analysis to urban planning. In this sense, it has deepened the neoliberal governance of urban space. Critical geographers have studied socio-spatial conflicts generated by the expansion of logistics. For example, the decline of shopping malls — called the 'dead malls' phenomenon in Parlette and Cowen [46] — has fuelled local activism forms representing malls as 'community spaces.' Specific North American poor neighborhoods mobilize to defend these spaces because they find them essential for social reproduction, consumption, and leisure.

\section{CONCLUSIONS}

Both socio-spatial relations, on the one hand, and logistics activity, on the other, have been topics widely studied and analyzed from different perspectives, mainly for observing the impact of logistics economic industry on the urban space. However, the evolution of transport geography in the last years has favored a new type of analysis according to which the spatial organization of economic activities is a central issue. Since the beginning of the twenty-first century, the scientific interest within regional geography has focused on the interrelation between logistics and space, leading to a progressive increase in academic production. This review aimed at studying the tendencies in the scientific production about the intersection of both topics, identifying the main research lines, its evolution, and the relevance of them in terms 
of volume of academic productivity.

This article responds to three research questions presented in the first section. The article has analyzed the academic literature on logistics' spatiality in the Web of Science Core Collection between 2000 and 2020 (Q1). The study of interrelations among keywords demonstrated the existence of four different clusters of literature: cluster 1 is formed by publications related to the categories economics, politics, and logistics; cluster 2 by papers related to urbanism in industry and innovation; cluster 3 shows concepts related to systems, challenges, and design; cluster 4 highlights concepts related to transportation and sustainability. The analysis also showed that globalization and industry concepts were gradually substituted by sustainability, streamlining, and technology. In fact, the conceptual analysis showed the prevalence of the term "city", connected with "planning" and "sustainability". The analysis also demonstrated that the literature is currently especially concerned with sustainability (something reflected in the rise of concepts such as "green spaces" and "urban-heatislands".

Regarding the second research question (Q2), what types of logistics activities are most studied from a spatial perspective, the analysis showed that most research focused on transportation (mainly urban freight/earth transportation and studies that included several means of transportation) concerning the type of logistics activity. Warehousing and reverse logistics were less analyzed. Consequently, the analysis shows that this field of research has tended to focus on the socio-spatial impact of transport and its impact on the urban environment. It can also be infered that logistics has tended to be studied from a cost-benefit model, relegating sustainability in urban planning to a secondary position.

The third question (Q3) refers to the impact of logistics on the organization of the urban space according to the specialized literaure. The analysis suggests that the publications related to economics, politics, and globalization are dominant. These publications have explored the interlinks among economic globalization, logistics, and urban transformation and planning. Besides, in the last years they include the discussion on the most efficient location of warehousing and transport activity within cities. A minor and recent part of this literature has also paid attention to environmental challenges and socio-spatial conflicts of the expansion of logistics. Authors have studied how logistics provide a cost-benefit model for organizing the urban space and how activists confront the logistics revolution's spatial consequences. Speaking about socio-spatial conflicts implies thinking of social reality as a process defined by the entanglement of multiple factors, both physical and symbolic, and subject to constant dynamics of socio-economic and power relationships [47].

The equilibrium of the interrelations among physical, symbolic, economic and political factors has been widely treated in the 17 Sustainable Development Goals 2030. And for the particular case of the cities that rely on logistics activity, the literature suggests that there exist specific conflicts around the equilibrium between sustainability and competitiveness on a global scale. Socio-spatial conflict, as has been showed, can be explained within the frame of the globalized and neoliberal city's spatial reorganization, in which the discourse about competitiveness prevails over the discourse on sustainability.

This study is one of the first attempts to map 'logistics, planning, and sustainability' applying bibliometric techniques. Although logistics inquiry has a longstanding tradition, the analysis has demonstrated that this field has not begun to address sustainability until the last years. Indeed, the field has evolved at a rapid pace, mainly in the previous five years. It has experienced significant growth, probably with the greater social concern fostered by the United Nations and the Sustainable Development Goals 2030.

Specific weaknesses of this revision will be addressed in further research on particular cases of cities paying attention to socio-spatial conflicts, and the implications of the spread of logistics from a critical perspective, including the articulation among several types of logistics activities and infrastructures. Another relevant domain of further research in logistics inquiry are the reasons behind the decline in the study of globalization and politics, as well the current increase of planning and sustainability. These domains of research are changing in the last years, but given the growing importance of logistics in urban landscape, it can be expected that they will gain centrality in the years to come.

\section{ACKNOWLEDGMENT}

This work was supported by the European CommisionErasmus+ Programme under Grant 611583-EPP-1-2019-1ES-EPPJMO-MODULE; and the Instituto Universitario para el Desarrollo social y Sostenible (INDESS) of the University of Cádiz. The authors would like to thank Iban Diaz-Parra for his valuable suggestions on previous draft of the manuscript and to the help of Alex Aguirre and Álvaro García Rosa with different stages of the research process.

\section{REFERENCES}

[1] Hesse, M., Rodrigue, J.P. (2006). Global production networks and the role of Logistics and Transportation. Growth and Change, 37: 499-509. https://doi.org/10.1111/j.1468-2257.2006.00337.x

[2] Aized, T., Srai, J.S. (2014). Hierarchical modelling of Last Mile logistic distribution system. The International Journal of Advanced Manufacturing Technology, 70(58): 1053-1061. https://doi.org/10.1007/s00170-013-5349

[3] Taniguchi, E., Thompson, R., Yamada, T. (2016). New opportunities and challenges for city logistics. Transportation Research Procedia, 12: 5-13. https://doi.org/10.1016/j.trpro.2016.02.004

[4] Ranieri, L., Digiesi, S., Silvestri, B., Roccotelli, M. (2018). A review of last mile logistics innovations in an externalities cost reduction vision. Sustainability, 10(3): 782. https://doi.org/10.3390/su10030782

[5] Huws, U. (2014). Labour in the Global digital Economy: The Cybertariat Comes of Age. New York, NY, NYU Press.

[6] Graham, M., Hjorth, I., Lehdonvirta, V. (2017). Digital Labour and development: Impacts of global digital Labour platforms and the gig economy on worker livelihoods. Transfer: European Review of Labour and Research, 23(2): 135-162. https://doi.org/10.1177/1024258916687250

[7] Muñoz, K.M., Medina, P.A. (2020). Precarización de plataformas: El caso de los repartidores a domicilio en España Precarization of platforms: The case of couriers in Spain, Psicoperspectivas, 19(1): 1-12. https://doi.org/10.5027/psicoperspectivas-Vol19-Issue1- 
fulltext-1680

[8] Johnston, H. (2020). Labour geographies of the platform economy: Understanding collective organizing strategies in the context of digitally mediated work. International Labour $\quad$ Review, 159(1): 25-45. https://doi.org/10.1111/ilr.12154

[9] Sassen, S. (2001). Global cities and developmentalist states: How to derail what could be an interesting debate: A Response to Hill and Kim. Urban Studies, 38(13): 2537-2540.

https://doi.org/10.1080/00420980120094650

[10] Smith, M.P. (2001). Transnational Urbanism. Locating Globalization. Oxford, Blackwell.

[11] Scott, A., Storper, M. (1992). Pathways to Industrialisation, London, Routledge.

[12] O'Connor, K. (2010). Global city regions and the location of logistics activity. Journal of Transport Geography, $\quad$ 18(3): 354-362. https://doi.org/10.1016/j.jtrangeo.2009.06.015

[13] Stevens, L., Shearmur, R. (2020). The end of location theory? Some implications of micro-work, work trajectories and gig-work for conceptualizing the urban space economy. Geoforum, 111: 155-164. https://doi.org/10.1016/j.geoforum.2020.02.010

[14] Stehlin, J., Hodson, M., McMeekin, A. (2020). Platform mobilities and the production of urban space: Toward a typology of platformization trajectories. Environment and Planning A: Economy and Space, 52(7): 1250-1268. https://doi.org/10.1177/0308518X19896801

[15] Peck, J., Theodore, N. (2007). Variegated capitalism. Progress in Human Geography, 31(6): 731-772. https://doi.org/10.1177/0309132507083505

[16] Cooper, H., Hedges, L., Valentine, J. (2009). The handbook of research synthesis and meta-analysis. New York, NY, Russell Sage Foundation.

[17] Pickering, C., Byrne, J. (2014). The benefits of publishing systematic quantitative literature reviews for $\mathrm{PhD}$ candidates and other early career researchers. Higher Education Research \& Development, 33(3): 534548. https://doi.org/10.1080/07294360.2013.841651

[18] Wakefield, A. (2015). Synthesising the literature as part of a literature review. Nursing Standard, 29: 44-51. https://doi.org/10.7748/ns.29.29.44.e8957

[19] Cheng, M., Edwards, D., Darcy, S., Redfern, K. (2018). A tri-method approach to a review of adventure tourism literature: Bibliometric analysis, content analysis, and a quantitative systematic literature review. Journal of Hospitality \& Tourism Research, 42(6): 997-1020. https://doi.org/10.1177/1096348016640588

[20] Jiménez-García, M., Ruiz-Chico, J., Peña-Sánchez, A.R., López-Sánchez, J.A. (2020). A Bibliometric Analysis of 598 Sports Tourism and Sustainability (2002-2019). Sustainability, 12(7): https://doi.org/10.3390/su12072840

[21] Liu, H., Liu, Y., Wang, Y., Pan, C. (2019). Hot topics and emerging trends in tourism forecasting research: A scientometric review. Tourism Economics, 25: 448-468. https://doi.org/10.1177/1354816618810564

[22] Van Raan, A.F.J. (2005). For your citations only? Hot topics in bibliometric analysis. Measurement: Interdisciplinary Research and Perspectives, 3: 50-62. https://doi.org/10.1207/s15366359mea0301_7

[23] Zhang, X., Chen, H., Wang, W., Ordónez, P. (2016). What is the role of IT in innovation? A bibliometric analysis of research development in IT innovation. Behaviour \& Information Technology, 35: 1130-1143. https://doi.org/10.1080/0144929X.2016.1212403

[24] Linnenluecke, M.K., Marrone, M., Singh, A.K. (2019). Conducting systematic literature reviews and bibliometric analyses, Australian Journal of Management, $\quad$ 45(2): 175-194 https://doi.org/10.1177/0312896219877678

[25] Jiang, Y., Ritchie, B.W., Benckendorff, P. (2019). Bibliometric visualisation: An application in tourism crisis and disaster management research. Current Issues in Tourism, 22(16): 1925-1957. https://doi.org/10.1080/13683500.2017.1408574

[26] Van Eck, N.J., Waltman, L. (2020). Vosviewer software, version 1.6. 14. Centre for Science and Technology Studies: Leiden, The Netherlands.

[27] Niñerola, A., Sánchez-Rebull, M.V., Hernández-Lara, A.B. (2019). Tourism research on sustainability: A bibliometric analysis. Sustainability, 11(5): 1377. https://doi.org/10.3390/su11051377

[28] López-Bonilla, J.M., Reyes-Rodríguez, M.C., LópezBonilla, L.M. (2018). The environmental attitudes and behaviours of European golf tourists. Sustainability, 10(7): 2214. https://doi.org/10.3390/su10072214

[29] López-Bonilla, J.M., Reyes-Rodríguez, M.D.C., LópezBonilla, L.M. (2020). Interactions and relationships between personal factors in pro-environmental golf tourist behaviour: A gender analysis. Sustainability, 12(1): 332. https://doi.org/10.3390/su12010332

[30] López-Bonilla, J.M., López-Bonilla, L.M. (2012). Environmental orientation in tourism: The RTEO scale. Current Issues Tourism, 15(6): 591-596. https://doi.org/10.1080/13683500.2012.657615

[31] Milian, R.P., Mclaughlin, N. (2017). Canadian sociology for sale? Academic branding in the 'Neo-Liberal Age'. The American Sociologist, 48(2): 172-191. https://doi.org/10.1007/s12108-016-9318-9

[32] Cidell, J. (2010). Concentration and decentralization: The new geography of freight distribution in US metropolitan areas. Journal of Transport Geography, 18(3):

https://doi.org/10.1016/j.jtrangeo.2009.06.017

[33] Aljohani, K., Thompson, R.G. (2016). Impacts of logistics sprawl on the urban environment and logistics: Taxonomy and review of literature. Journal of Transport Geography, 57: 255-263. https://doi.org/10.1016/j.jtrangeo.2016.08.009

[34] Zacharias, J., Tang, Y. (2010). Restructuring and repositioning Shenzhen, China's new mega city. Progress in Planning, 73(4): 209-249. https://doi.org/10.1016/j.progress.2010.01.002

[35] Vlachopoulou, M., Silleos, G., Manthou, V. (2001). Geographic information systems in warehouse site selection decisions. International Journal of Production Economics, 71(1-3): 205-212. https://doi.org/10.1016/S0925-5273(00)00119-5.

[36] Ferri, G.L., Chaves, G.D.L.D., Ribeiro, G.M. (2015). Reverse logistics network for municipal solid waste management: The inclusion of waste pickers as a brazilian legal requirement. Waste Management, 40: 173-191. https://doi.org/10.1016/j.wasman.2015.02.036

[37] Muñuzuri, J., Cortés, P., Guadix, J., Onieva, L. (2012). City logistics in Spain: Why it might never work. Cities, 29:

133-141. 
https://doi.org/0.1016/J.CITIES.2011.03.004

[38] Allen, J., Browne, M., Cherrett, T.J. (2012). Investigating relationships between road freight transport, facility location, logistics management and urban form. Journal of Transport Geography, 24: 45-57. https://doi.org/10.1016/j.jtrangeo.2012.06.010

[39] Poelmans, L., Van Rompaey, A. (2010). Complexity and performance of urban expansion models. Computers, Environment and Urban Systems, 34(1): 17-27. https://doi.org/10.1016/j.compenvurbsys.2009.06.001

[40] Lee, S.W., Song, D.W., Ducruet, C. (2008). A tale of Asia's world ports. Geoforum, 39(1): 372-385. https://doi.org/10.1016/j.geoforum.2007.07.010

[41] Hoyle, B. (2000). Global and Local Change on the Portcity Waterfront, Geographical Review, 90(3): 395-417. https://doi.org/10.2307/3250860

[42] Krzysztofik, R., Kantor-Pietraga, I., Spórna, T., Dragan, W., Mihaylov, V. (2019). Beyond 'logistics sprawl' and 'logistics anti-sprawl'. Case of the Katowice region, Poland. European Planning Studies, 27(8): 1646-1660. https://doi.org/10.1080/09654313.2019.1598940
[43] Scoot, A. (2008). Social Economy of the Metropolis. Cognitive-Cultural Capitalism and the Global Resurgence of Cities. Oxford, Oxford University Press. https://doi.org/10.1093/acprof:oso/9780199549306.001. 0001

[44] Taniguchi, E. (2014). Concepts of city logistics for sustainable and liveable cities. Procedia - Social and Behavioral Sciences, 151(30): 310-317. https://doi.org/10.1016/j.sbspro.2014.10.029

[45] Cowen, D. (2010). A geography of logistics: market authority and the security of supply chains. Annals of the Association of American Geographers, 100(3): 600-620. https://doi.org/10.1080/00045601003794908

[46] Parlette, V., Cowen, D. (2011), Dead malls: Suburban activism, local spaces, global logistics. International Journal of Urban and Regional Research, 35(4): 794-811. https://doi.org/10.1111/j.1468-2427.2010.00992.x

[47] Novoa, E. (2016). Geografías de la diferencia. Espacialidad, política y acción social. Bogotá D.C., Universidad Nacional de Colombia. 